\title{
Inquiry at Harvard prompts research paper corrections
}

San Diego. Three prominent physicians from Harvard Medical School working at the Children's Hospital in Boston have been forced to publish an extensive correction in connection with federally funded research on a treatment for rare, life-threatening birthmarks in infants.

The correction has been published in the New England Journal of Medicine (NEJM) after a lengthy investigation by Harvard into the conduct of the physicians, R. Alan B. Ezekowitz, John B. Mulliken and Judah Folkman. The latter is internationally renowned for his discoveries on angiogenesis, the process by which blood vessels grow.

It follows a briefer correction, published unilaterally last year by the three when the investigation was still under way, which included corrected data about some of the patients involved in the study, but without any accompanying comment - or even identification of the names of the authors.

The investigation concerned an article published in the NEJM $(326,1456-63 ; 1992)$ on the effectiveness of interferon alfa-2a in reducing large hemangiomas, growths that can occasionally block an infant's airway, affect its vision or compromise a vital organ.

The article, based on observations of 20 cases, claimed that the therapy had had a substantial effect. But Harvard officials say that after it was published, other physicians who had referred the children to the team complained about various inaccuracies. According to David Nathan, physicianin-chief at Children's Hospital, this prompted Harvard to set up an ad hoc committee to investigate possible misconduct, the first such probe at the 325-bed institution.

The committee found that there was no misconduct or fraud, says Nathan. But it did find many errors needing correction. These included the fact that some hemangiomas were reported to have regressed more than they did; that the lesions were not measured, as the article suggested; that some patients were not treated for the period reported; that prior therapies used on some patients were not listed correctly; and that monthly blood tests were not taken on all patients as reported, with the result that no conclusion could be reached on drug toxicity.

The results of Harvard's investigation were sent to the National Institutes of Health (NIH)'s Office of Research Integrity (ORI), which, according to Nathan, accepted the university's findings. But it appears that neither the National Cancer Institute (NCI), nor the National Center for Research Resources - the NIH agencies whose grants were cited as funding the research - was notified of the Harvard investigation or of any corrective actions.
Collette Freeman, the NCI grant officer, described the situation as "extraordinary" and "bizarre" when told of the correction.

Harvard officials refuse to comment on the case, or to say whether any sanctions were issued against the researchers. Nor were any of the three physicians prepared to comment. But in their correction, published on 31 August, they wrote: "We are embarrassed by our errors and regret them. We apologize to the readers for any misunderstanding and thank our colleagues for their assistance in correcting our report."

Nathan called the interferon research "a very important paper" by "distinguished investigators". But, he claims, the researchers "got very busy" and "just slapped this paper together". He accepts that almost all the errors in the eight-page article tend to improve the apparent success of the therapy. "That is how the original complaint was made," says Nathan. "It is curious that it turned out that way."

The lengthy investigation appears to have been marked by contention, defiance by the researchers and anger. Nathan says that when the Harvard review started, the three "became very irritable", submitting material for correction to the journal against his advice. "The first correction wasn't certified by Harvard," said Nathan. "I felt it was wiser to be patient, collect all the errors and deal with them in one fell swoop," he says, adding that the medical school feels strongly that corrections have to be certified by the institution.

Jerome P. Kassirer, who took over as editor-in-chief at the NEJM after the first correction was published, says that the Harvard researchers submitted "material that was very confusing" for this correction. Earlier this year, he says, the three physicians submitted further material, approved by Harvard, but this was little easier to interpret. "The editors had a great deal of trouble figuring out what they were driving at."

Despite the errors, Nathan said the conclusions of the study remain valid, and that interferon remains the preferred therapy for such hemangioma cases. But some physicians feel a random, prospective study is still required to back up this conclusion, as the lesions are known to regress on their own as children age.

"I have to express reservations about any non-randomized study, especially one in which it now appears that the data was brushed up," says Ajay J. Vora, a paediatric haematologist at Children's Hospital in Sheffield, in the United Kingdom, who originally questioned the interferon study in a letter to the NEJM in October 1992.

Rex Dalton

\section{US plays hard to get as Unesco continues to woo support}

Paris. Even hardened spectators of the long-running saga over whether the United States will rejoin the United Nations Educational Cultural and Scientific Organization (Unesco) - which it left in 1984, complaining of chronic mismanagement and anti-Western bias - are confessing bemusement at the latest chapter.

Speaking at a press lunch in Paris last week, Federico Mayor, the director general of the UN agency, claimed that President Bill Clinton had written to him in January saying the United States was prepared to

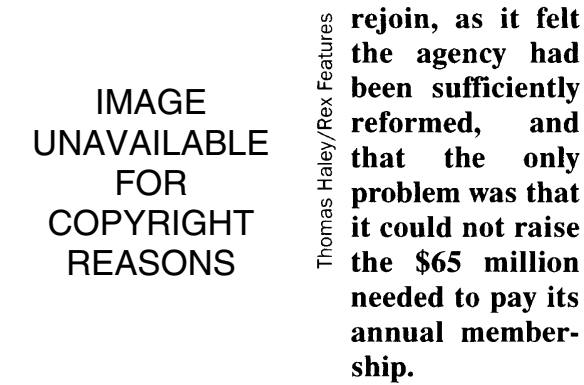

Mayor: wants backing from the United States.

But the official US position appears less clear-cut. Recommendations from a government task force in 1993 that the United States should rejoin has never been formally endorsed by the administration. Moreover, says one State Department official, the election of a Republican majority in Congress, keen to cut payments to international agencies, means that the chances of rejoining Unesco in the near future are virtually zero.

The official also gives a somewhat different account of the events described by Mayor. He says that Mayor understood that the domestic US political scene ruled out the United States rejoining Unesco soon, but was concerned that the other member states might conclude that "there must be something wrong with Unesco if the US is staying out".

Mayor therefore asked the US administration to help to boost Unesco's credibility by issuing a statement saying it was satisfied with the reforms at the agency, according to the official.

One formula being considered is that used by Clinton in his letter in which he "applauded the substantial progress" being made by Unesco in addressing the problems that led to US withdrawal.

This letter was not in fact addressed to Mayor, as the latter claimed, but to Cyrus Vance, co-chairman of the national council of the US United Nations Association, who had earlier written to Clinton asking him to include funding for Unesco membership in the 1996 budget.
Declan Butler 